\title{
EFFICIENT ADSORPTION OF Ce (III) ONTO POROUS CELLULOSE/GRAPHENE OXIDE COMPOSITE MICROSPHERES PREPARED IN IONIC LIQUID
}

\author{
YAN HAO, ${ }^{*}$ JING QU, ZUNYI LIU, ${ }^{*}$ SONGBO LI, HUI YANG, ${ }^{*}$ HUAZHENG SAI, \\ HUIMIN YANG, ${ }^{*}$ JING PENG, ${ }^{* *}$ LONG ZHAO ${ }^{* * *}$ and MAOLIN ZHAI** \\ "Institute of Applied Chemistry School of Chemistry and Chemical Engineering, \\ Inner Mongolia University of Science and Technology, No. 7 Arden Str., Baotou 014010, P.R. China \\ ** Key Laboratory of Polymer Chemistry and Physics of the Ministry of Education, College of Chemistry and \\ Molecular Engineering, Beijing National Laboratory for Molecular Sciences, \\ Peking University, Beijing 100871, P.R. China \\ ${ }^{* * * *}$ Institute of Applied Electromagnetic Engineering, Huazhong University of Science and Technology, \\ Wuhan 430074, P. R. China \\ $\bowtie$ Corresponding authors: Yan Hao, haoyannk@163.com \\ MaolinZhai,mlzhai@pku.edu.cn
}

Received July 8, 2021

\begin{abstract}
A novel adsorbent made of porous cellulose/graphene oxide composite microspheres (PCGCM) was synthesized in $[\mathrm{Bmim}] \mathrm{Cl}$ ionic liquid. The as-prepared PCGCM was evaluated for the removal of Ce (III) via static adsorption experiments. The results showed that the adsorption equilibrium of Ce (III) onto PCGCM was achieved within 50 min and the adsorption was highly $\mathrm{pH}$ dependent. An excellent adsorption capacity as high as $415.1 \mathrm{mg} \cdot \mathrm{g}^{-1}$ was obtained at a $\mathrm{pH}$ of 4.9, which was much higher than most adsorbents reported in the literature. The pseudo-second order kinetic model and Langmuir isotherm model were found to fit the adsorption behavior of PCGCM well. The XPS analysis confirmed that the adsorption was based on the ion exchange mechanism. Meanwhile, PCGCM could be regenerated with $1 \mathrm{~mol} \cdot \mathrm{L}^{-1} \mathrm{HCl}$ for repetitious adsorption of $\mathrm{Ce}$ (III). This work provides an attractive approach for the removal of rare earth ions as pollutants.
\end{abstract}

Keywords: graphene oxide, microspheres, cellulose, ionic liquid, Ce (III) removal

\section{INTRODUCTION}

In recent years, rare earth ions (REEs) have been in great demand in many important industries, such as electronics, nuclear energy, computers and chemical engineering. ${ }^{1}$ However, REEs can be toxic and have a strong impact on the environment and human health when the REE-containing wastes are not properly treated and released into the global ecosystem. REEs, such as Cerium [Ce (III)], can accumulate in multiple organs and are hard to remove as they enter the human body. It has been found that REEs can have adverse effects on the intelligence quotient and memory of children, as trace rare earth ions affect the central nervous system through the blood brain barrier. ${ }^{2}$ It is therefore critical to eliminate REEs from wastewater before it is discharged into the environment.

Adsorption, $^{3}$ liquid-liquid extraction ${ }^{4}$ and solid-liquid extraction ${ }^{5}$ are considered to be the main methods to preconcentrate and separate $\mathrm{Ce}$ (III). Among these methods, adsorption is preferable owing to its convenience for operation, high efficiency, low cost, and no secondary pollution during the adsorption process. ${ }^{6}$ The key component in the adsorption process is to find the appropriate adsorbents for REEs. Graphene oxide (GO) is a promising adsorbent that has attracted increasing attention due to many excellent properties, such as large surface area and outstanding mechanical properties. ${ }^{7,8}$ In addition, a great quantity of oxygen atoms, such as epoxy, 
hydroxyl, and carboxyl groups, exist on the surface of GO, which can efficiently bind metal ions to form the metal complex via their lone electron pairs and significantly improve the adsorption capacity of GO. ${ }^{9}$ Sadeghi et al. synthesized graphene oxide nanoribbons (GONRs) for adsorption removal of $\mathrm{As} \mathrm{(V)} \mathrm{and} \mathrm{Hg}$ (II). The maximum monolayer adsorption capacity of GONRs reached $2000 \mathrm{mg} \cdot \mathrm{g}^{-1}$ for As (V) and 44 $\mathrm{mg} \cdot \mathrm{g}^{-1}$ for Hg (II). ${ }^{10}$ Tohamy et al. functionalized GO by ethylene diamine tetra-acetic acid (EDTA) via a hydrothermal process. The prepared adsorbents exhibited a steadily increasing adsorption of $\mathrm{Ni}$ (II) ions until $45 \mathrm{~min} .{ }^{11}$ However, the stable suspensions and small particles formed by GO in solution usually cause high pressure in the filtration process, which has hindered its practical application as adsorbent. ${ }^{12}$ To overcome this problem, GO is often mixed with other biopolymers, such as cellulose, to form a composite. ${ }^{13,14}$

Cellulose, one of the most abundant natural biopolymers, has many desirable properties as an co-absorbent, such as renewability, biodegradability and low cost. ${ }^{15}$ Recently, several studies have shown that cellulose can be stabilized with GO as a matrix via hydrogen bonds. ${ }^{16,17}$ After mixing with GO to form a composite, the mechanical and thermal properties of cellulose are greatly enhanced, whereas the manufacturing cost of GO can also be reduced for broader applications. ${ }^{18}$ Thus, to combine the adsorption property of cellulose and the special characteristics of GO, numerous efforts have been made to prepare cellulose/GO composites for the removal of pollutants from water, such as malachite green dye, ${ }^{19}$ methylene blue, ${ }^{20}$ and metal ions. ${ }^{12,14}$

One key issue for cellulose is that it does not dissolve in common solvents because of its intraand inter-molecular hydrogen bonds. ${ }^{21}$ Many non-conventional solvents have been developed to dissolve cellulose. For the past few years, ionic liquids (ILs) have been considered as effective solvents for cellulose due to their excellent dissolution ability, negligible vapor pressure, recyclability, lower hydrophobicity, variations of structures, enhanced electrochemical stability, and thermal stability. ${ }^{22,23}$ As novel cellulose solvents, ILs have been widely used in the preparation of various regenerated cellulose materials and cellulose-based composites for many applications. ${ }^{9,24}$
In our previous work, a cellulose/GO composite film adsorbent was prepared in ILs and the highest adsorption capacity achieved for $\mathrm{Ce}$ (III) ions was $109.1 \mathrm{mg} \cdot \mathrm{g}^{-1}$, which has left room for improvements. ${ }^{25}$ To develop the next generation of adsorbents for REEs, we envisioned that a cellulose/GO composite in the microsphere format could afford high adsorption capacity, fast kinetics and excellent reusability. Moreover, a porous structure can provide high adsorption capacity for hazardous ions due to connected pores and high surface area. ${ }^{26}$ Herein, we synthesized a series of porous cellulose/GO composite microspheres (PCGCM) by dropwise addition of the composite of cellulose and GO into water. The cellulose/GO composites were prepared by using 1-butyl-3-methylimidazolium chloride $([\mathrm{Bmim}] \mathrm{Cl})$ ionic liquid, which provided excellent cellulose solubility and GO dispersity. To investigate the adsorption behavior of PCGCM, adsorption isotherm, adsorption kinetics, adsorption capacities at various initial solution $\mathrm{pH}$ were studied using Ce (III) as a model pollutant. We believe this work can contribute to the development of the next generation of bioadsorbents in REEs wastewater treatment.

\section{EXPERIMENTAL}

\section{Materials}

$[\mathrm{Bmim}] \mathrm{Cl}(>99 \%)$ was provided by Lanzhou Institute of Chemical Physics. GO was purchased from Changzhou Sixth Element Materials Technology Research Institute. Microcrystalline cellulose (MCC) was provided by Tianjin Guangfu Fine Chemical Research Institute. Cerium nitrate $\left(\mathrm{Ce}\left(\mathrm{NO}_{3}\right)\right)$ was purchased from Tianjin Damao Chemical Reagent Factory. Arsenazo III was purchased from Meryer Chemical Technology Co., Ltd.

\section{Preparation of adsorbents}

The preparation process of adsorbents is shown in Scheme 1. [Bmim]Cl $(20.0 \mathrm{~g})$ was heated at $100{ }^{\circ} \mathrm{C}$ and MCC (2.0 g) was slowly added with stirring to completely dissolve it for $24 \mathrm{~h}$. The obtained cellulose/[Bmim]Cl solution was divided into two parts: one part was added dropwise into deionized water at a rate of $1 \mathrm{~mL} \cdot \mathrm{min}^{-1}$ to obtain regenerated cellulose microspheres (RCM); the other part was used to mix with GO.

Meanwhile, GO $(0.33 \mathrm{~g})$ was dispersed in DMSO $(2.97 \mathrm{~g})$ by the ultrasonic treatment $\left(60^{\circ} \mathrm{C}, 100 \mathrm{~W}\right)$ for $1 \mathrm{~h}$. Subsequently, the GO/DMSO dispersion was added to the cellulose/[Bmim]Cl solution with stirring at $100{ }^{\circ} \mathrm{C}$ for 30 minutes, then it was treated with ultrasound $\left(100 \mathrm{~W}, 60^{\circ} \mathrm{C}\right)$ for $3 \mathrm{~h}$. The obtained 
mixture was added dropwise into deionized water at the rate of $1 \mathrm{~mL} \cdot \mathrm{min}^{-1}$ to form PCGCM.

Two adsorbents were prepared and used in further lot size experiments. The mass ratios of cellulose and GO in PCGCM-I and PCGCM-II were 3:1 and 2:1, respectively. After that, the resulting microspheres were cleaned with deionized water several times to remove $[\mathrm{Bmim}] \mathrm{Cl}$, until the $\mathrm{AgNO}_{3}$ reaction test indicated absence of $\mathrm{Cl}^{-}$, which could also be confirmed by the nitrogen content from elemental analysis using an Element Analyzer (EA) (Elementar Vario MICRO CUBE). The products were then placed in a freeze-drying container (model: SCIENTZ-10N) and freeze-dried for $24 \mathrm{~h}$ under vacuum. All the adsorbents were stored in a desiccator for further analysis.

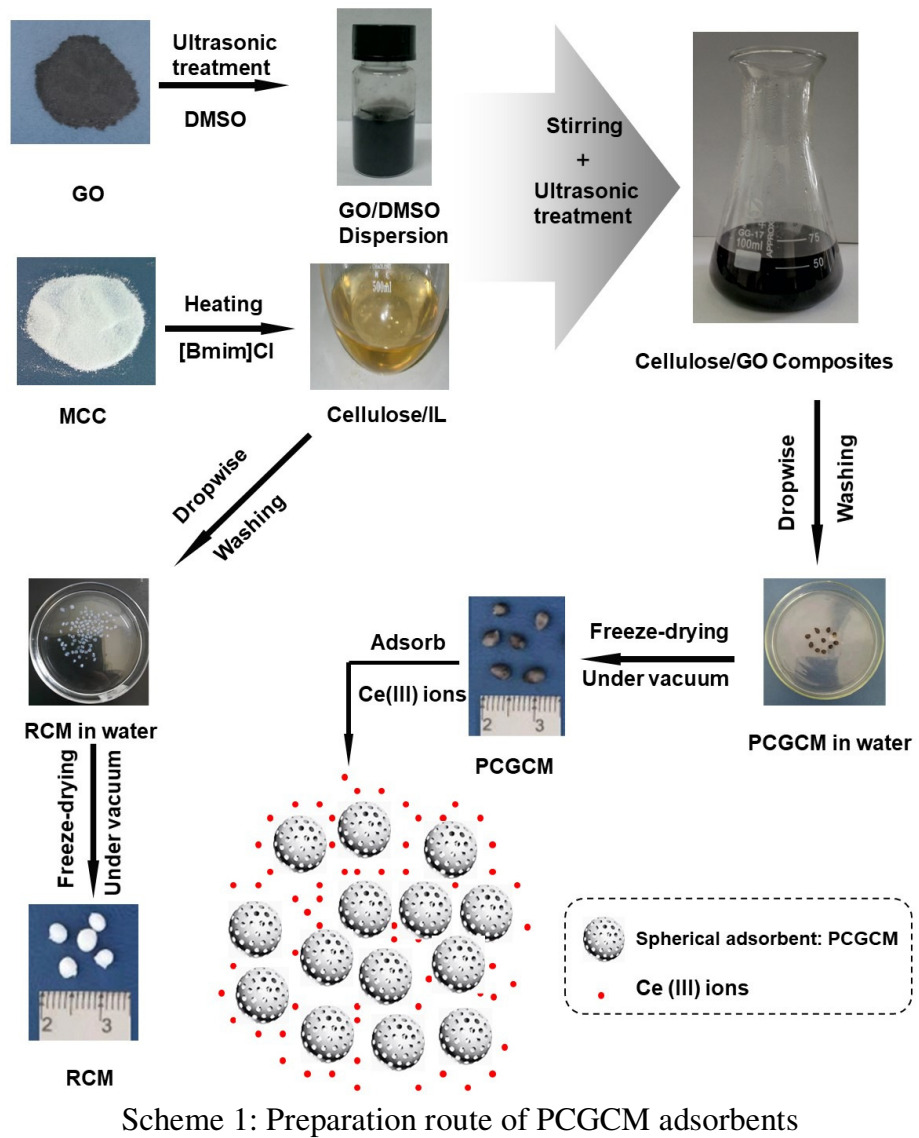

\section{Characterization of PCGCM}

Fourier-transform infrared spectroscopy (FTIR, Spotlight200, Nicolet) was used to characterize the original MCC, GO, RCM and PCGCM. In the absorption mode, FTIR spectra were determined within the range of $4000-650 \mathrm{~cm}^{-1}$.

The thermal stability of the samples from ambient temperature up to $700{ }^{\circ} \mathrm{C}$ was studied by a thermogravimetric analyzer (SDT Q50, TA Instrument, USA) at the heating rate of $10{ }^{\circ} \mathrm{C} \cdot \mathrm{min}^{-1}$ in nitrogen atmosphere.

For the measurement of compressive strength, the samples were cut into a cuboid shape $(20 \times 20 \times 40 \mathrm{~mm})$. Then, the compressive strength of the samples, along the compressive direction, was measured by a dynamic mechanical analyzer at the compression rate of 0.5 $\mathrm{mm} \cdot \mathrm{min}^{-1}$ (HD-B609B-S, Haida Equipment Co. Ltd., Dongguan, China). The Young's modulus of the samples was evaluated from up to $10 \%$ of the stress-strain curve.

The X-ray diffraction (XRD) analysis was carried out by an XRD-Multiflex (Rigaku Corporation, Japan), which used $\mathrm{Ni}$-filtered $\mathrm{CuK}$, with a sweeping range of $10^{\circ}-50^{\circ}$ and a scanning speed of $2^{\circ} \cdot \mathrm{min}^{-1}$.

The X-ray photoelectron spectroscopy (XPS) analysis was conducted on an AXIS-Ultra instrument of Kratos Analysis Company, and the charge compensation was carried out by using monochromatic Al $\mathrm{K}_{\alpha}$ radiation $(225 \mathrm{~W}, 15 \mathrm{~mA}, 15 \mathrm{kV})$ and low-energy electron injection. To compensate for the influence of surface charge, the binding energies were corrected by the binding energy (BE) of $\mathrm{C} 1 \mathrm{~s}$ hydrocarbon peak at $284.8 \mathrm{eV}$. The data was converted to the VAMAS file format and imported to the CASA XPS software for data processing and curve fitting. 


\section{Adsorption of Ce (III) onto adsorbents}

The adsorption of Ce (III) was studied by the batch adsorption method. All experiments were carried out at room temperature. $\mathrm{Ce}\left(\mathrm{NO}_{3}\right)_{3}$ was dissolved in $\mathrm{HNO}_{3}$ $\left(0.01 \mathrm{~mol} \cdot \mathrm{L}^{-1}\right)$ to obtain the $\mathrm{Ce}$ (III) standard stock solution $\left(2 \mathrm{mmol} \cdot \mathrm{L}^{-1}\right)$, which could prevent the precipitation of Ce (III) species. ${ }^{27}$ To study adsorption kinetics, $15.0 \mathrm{mg}$ of an adsorbent was added into 50 $\mathrm{mL}$ of aqueous solution containing $140 \mathrm{mg} \cdot \mathrm{L}^{-1} \mathrm{Ce}$ (III). After adsorption, the adsorbent was separated from the solution. Arsenazo III aqueous solution $(5 \mathrm{~mL}, 0.1$ $\mathrm{wt} \%$ ), and $10 \mathrm{~mL}$ of anhydrous alcohol were added into the residual $\mathrm{Ce}\left(\mathrm{NO}_{3}\right)_{3}$ solution. The effects of the $\mathrm{pH}$ value, the amount of adsorbents and $\mathrm{Ce}$ (III) concentrations on the absorption of $\mathrm{Ce}$ (III) were also studied following a similar procedure. $\mathrm{NH}_{3} \cdot \mathrm{H}_{2} \mathrm{O}(0.5$ $\left.\mathrm{mol} \cdot \mathrm{L}^{-1}\right)$ and $\mathrm{HNO}_{3}\left(0.01 \mathrm{~mol} \cdot \mathrm{L}^{-1}\right.$ and $\left.1 \mathrm{~mol} \cdot \mathrm{L}^{-1}\right)$ were used to adjust the $\mathrm{pH}$ value of the solution, which was determined by the $\mathrm{pH}$-meter (PHSJ-3F). The $\mathrm{pH}$ of the Ce (III) solution ranged from 1.3 to 8.4 , and the Ce (III) concentrations ranged from 14 to $140 \mathrm{mg} \cdot \mathrm{L}^{-1}$. The concentration of $\mathrm{Ce}$ (III) was measured by the Arsenazo III method at $655 \mathrm{~nm}$ by a UV-Visible spectrophotometer (Cintra 1010). ${ }^{28}$ The Ce (III) uptake $(q)$ was calculated by Equation (1):

$q=\left(C_{0}-C_{t}\right) \times V / m$

where $C_{0}$ and $C_{t}\left(\mathrm{mg} \cdot \mathrm{L}^{-1}\right)$ represent the concentrations of Ce (III) before and after adsorption, respectively; $m$ $(\mathrm{mg})$ is the mass of the adsorbent and $V(\mathrm{~mL})$ is the volume of Ce (III) solution.

\section{Desorption and regeneration}

The study of Ce (III) desorption was performed as follows: the PCGCM-I saturated with Ce (III) was soaked in $1 \mathrm{~mol} \cdot \mathrm{L}^{-1} \mathrm{NaCl}$ at $25{ }^{\circ} \mathrm{C}$ for 12 hours, washed three times with distilled water, and dried at 60 ${ }^{\circ} \mathrm{C}$ in a vacuum oven for $24 \mathrm{~h}$. The sample was then analyzed by XPS. To regenerate PCGCM-I, adsorbed Ce (III) ions were desorbed from PCGCM-I in $50 \mathrm{~mL}$ $\mathrm{HCl}$ solution $\left(1 \mathrm{~mol} \cdot \mathrm{L}^{-1}\right)$. Subsequently, the mixture solution was placed at room temperature for $12 \mathrm{~h}$. Then, PCGCM-I was washed with distilled water and dried in a vacuum oven at $60{ }^{\circ} \mathrm{C}(24 \mathrm{~h})$ before the next adsorption of $\mathrm{Ce}$ (III). The concentration of $\mathrm{Ce}$ (III) ions in the eluent was determined as described above. The same PCGCM-I was used for three consecutive adsorption-desorption cycles. All the experiments were done in duplicates and the mean values were reported.

\section{RESULTS AND DISCUSSION Characterization of PCGCM}

To confirm the formation of $\mathrm{GO}$ and cellulose composites, RCM, original MCC, GO and PCGCM-I were characterized by FTIR. As shown in Figure 1A, the FTIR spectrum of RCM was similar to that of the original MCC. The following characteristic bands were observed in the FTIR spectrum of the original MCC: the large absorption band in the range of $3300-3500 \mathrm{~cm}^{-1}$ represented the valence vibration of $\mathrm{OH}$ groups; the band in the range of $2700-2900 \mathrm{~cm}^{-1}$ belonged to $\mathrm{CH}_{2}$ groups; the peak at $1369 \mathrm{~cm}^{-1}$ corresponded to the bending vibration of the $\mathrm{C}-\mathrm{H}$ bond on the cellulose ring; the characteristic bands of $\mathrm{C}-\mathrm{O}-\mathrm{C}$ at $1156 \mathrm{~cm}^{-1}$ were attributed to glycosidic units. ${ }^{29}$ The FTIR spectrum of GO showed several characteristic peaks of oxygen-containing functional groups: the wide and strong bands within the range of 3700-3000 $\mathrm{cm}^{-1}$ were caused by the stretching vibrations of $-\mathrm{OH}$; the peak values of vibrations at 1036 and $1719 \mathrm{~cm}^{-1}$ corresponded to the $\mathrm{C}-\mathrm{O}-\mathrm{C}$ and $\mathrm{C}=\mathrm{O}$ stretching vibrations of carboxylic groups, respectively. ${ }^{30}$ In addition, the peak at $1613 \mathrm{~cm}^{-1}$ belonged to the $\mathrm{C}=\mathrm{C}$ stretching vibration of the aromatic skeleton of the unoxidized graphitic domains. ${ }^{31,32}$ The spectrum of PCGCM-I showed the characteristic peaks of both cellulose and GO. The peak at $3346 \mathrm{~cm}^{-1}$ was attributed to the stretching vibration of the $-\mathrm{OH}$ from both cellulose and GO. Moreover, due to the existence of $\mathrm{GO}$ in the cellulose matrix, the $-\mathrm{OH}$ peak of PCGCM-I shifted from 3346 to $3195 \mathrm{~cm}^{-1}$. It indicated that there was a strong hydrogen bonding between GO and cellulose. ${ }^{33}$ Compared with the control group, there was no significant change, except that the band at $1719 \mathrm{~cm}^{-1}$ in GO and RCM shifted to $1639 \mathrm{~cm}^{-1}$ in the case of PCGCM-I, which further indicated that GO was wrapped in PCGCM-I. ${ }^{19}$

In order to obtain the crystal structure information of $\mathrm{GO}$, original MCC, RCM and PCGCM-I, the XRD patterns were measured and shown in Figure 1B. The typical structure of cellulose I was shown by the MCC diffraction pattern. There was a sharp peak at $2 \theta=22.6^{\circ}$ and a wide peak at $14.9^{\circ}$, corresponding to (110) and (200) planes, respectively. ${ }^{34}$ After dissolution in [Bmim]Cl and subsequent coagulation with deionized water, RCM showed a wide diffraction peak at around $2 \theta=20.2^{\circ}$, which was attributed to the $(110) /(020)$ lattice planes of cellulose II crystalline structure. ${ }^{15}$ The experimental results indicated that after dissolution and regeneration in $[\mathrm{Bmim}] \mathrm{Cl}$, the crystalline structure of original MCC changed from cellulose I to cellulose II. $^{35}$ Moreover, compared with the original cellulose, the crystallinity of RCM reduced significantly. The results suggested that the ionic liquid destroyed intermolecular and intramolecular 
hydrogen bonds of the original MCC during dissolution. ${ }^{36}$ As shown in Figure 1B, GO had a unique diffraction peak at $11.4^{\circ}$, which could be attributed to the (001) plane. ${ }^{37}$ In addition, the
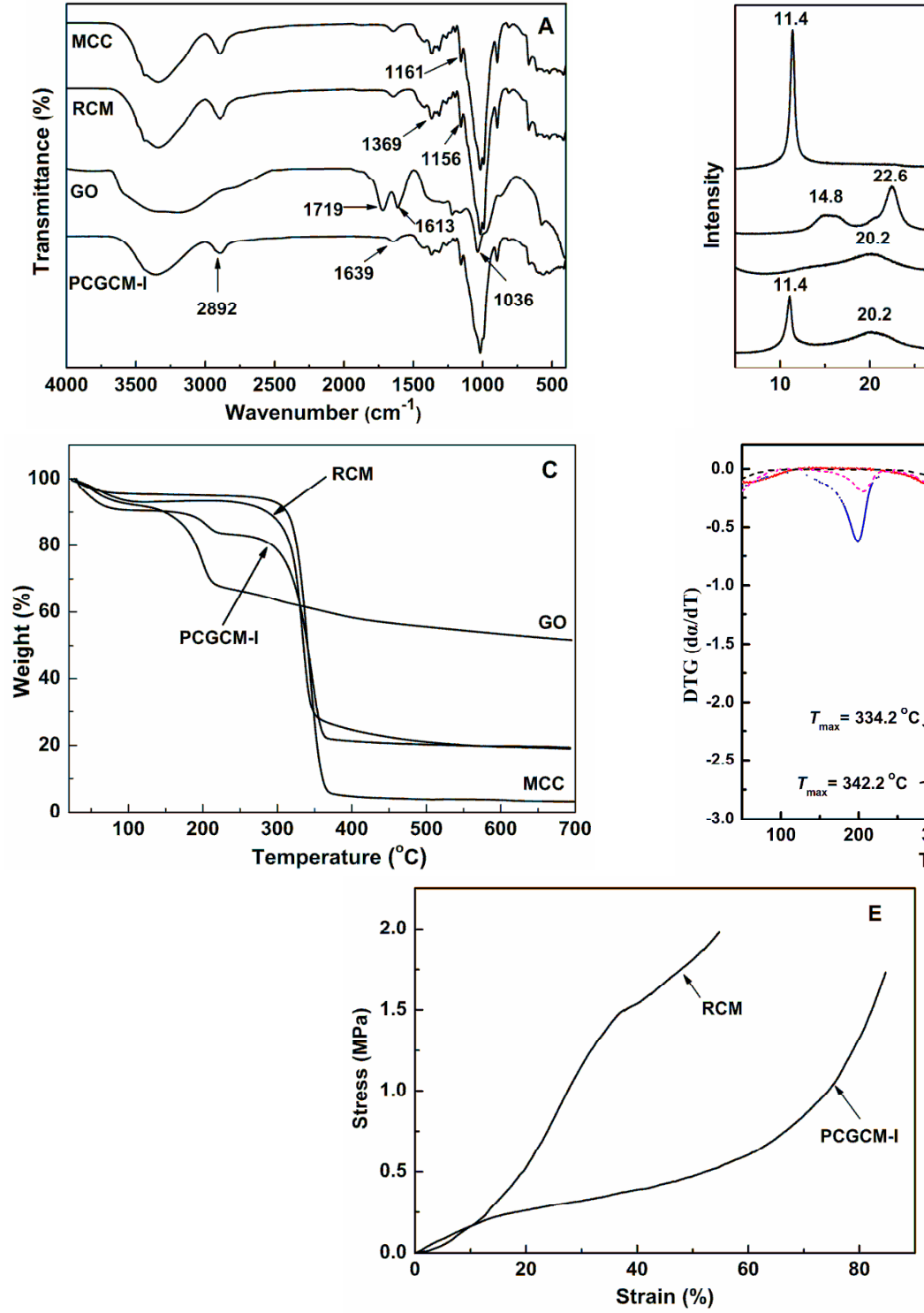

Figure 1: Micro-FTIR spectra (A), XRD patterns (B), TGA curves (C) and DTG curves (D) of GO, original MCC, RCM and PCGCM-I and stress-strain curves of RCM and PCGCM-I (E)

The thermal stability of the samples was investigated using TGA analysis. In the DTG curve (Fig. 1D), the temperature corresponding to the peak height is $T_{\max }$, which was $334.2{ }^{\circ} \mathrm{C}$ in RCM, compared with the $T_{\max }$ of $342.2{ }^{\circ} \mathrm{C}$ in the original MCC. The decrease of crystallinity during dissolution and regeneration of RCM led to the decrease of $T_{\max }{ }^{38}$ As shown in Figure 1C, it was also observed that the mass loss of GO over
PCGCM-I had a relatively small diffraction peak at $11.4^{\circ}$ and an obvious broad peak at about $20.2^{\circ}$, corresponding to GO and the regenerated cellulose, respectively.
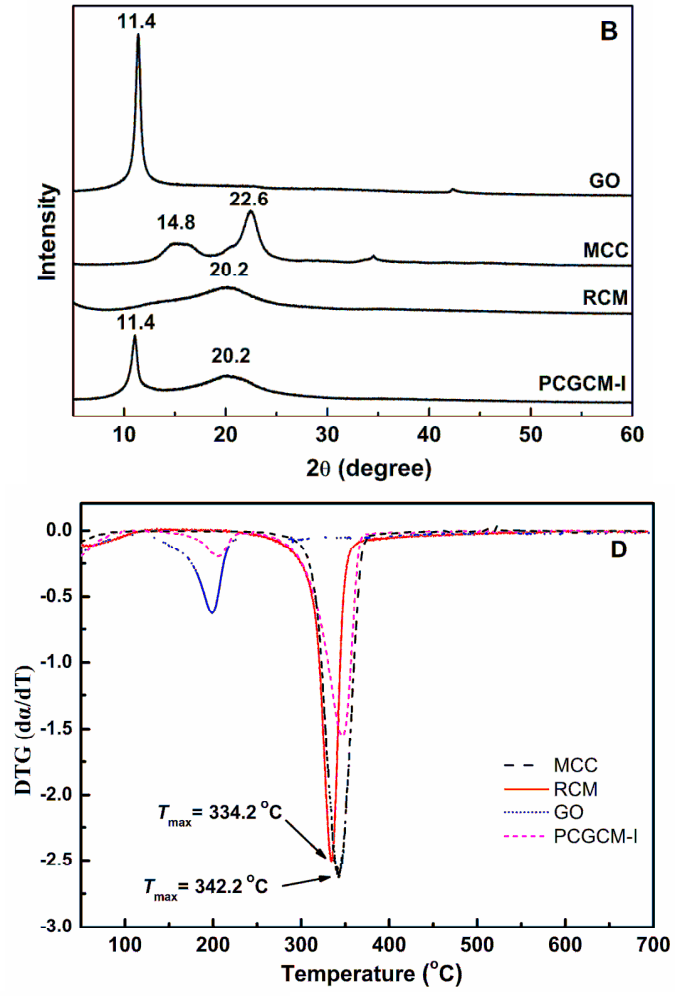

the temperature range from 120 to $250{ }^{\circ} \mathrm{C}$ was about $25.4 \mathrm{wt} \%$, which was attributed to the pyrolysis of unstable oxygen-containing groups in the forms of $\mathrm{CO}, \mathrm{CO}_{2}$ and steam. ${ }^{39}$ In comparison, the weight loss of PCGCM-I took place in three phases. The first phase from room temperature to $120{ }^{\circ} \mathrm{C}$ was due to the loss of water absorbed by the sample. The second phase occurred when the temperature increased from 120 to $250{ }^{\circ} \mathrm{C}$ due to 
the decomposition of oxygen-containing groups in GO. The third stage of weight loss $\left(>250{ }^{\circ} \mathrm{C}\right)$ was attributed to the decomposition of the chain, cellulose fragments, and monolayers in PCGCM-I. In addition, the char yield of RCM and PCGCM-I at $700{ }^{\circ} \mathrm{C}$ was about $19.0 \mathrm{wt} \%$ and $19.3 \mathrm{wt} \%$, respectively, whereas it was only $3.1 \mathrm{wt} \%$ for original MCC. The much higher char yield of RCM was caused by the formation of non-volatile carbonaceous substances. In the case of PCGCM-I, the interaction between cellulose and GO in the carbonization led to the higher char yield, which was similar to the interaction between cellulose and lignin. ${ }^{40}$

Compressive strength is one of the most important parameters to evaluate the performance of porous materials. The stress-strain curve of isotropic PCGCM-I (Fig. 1E) could be divided into three stages: (I) the linear elastic region under low strain condition $(<20 \%)$; (II) the plastic deformation region with a plateau at $20 \%-70 \%$ strain caused by irreversible bending of cellulose; (III) rapidly increased stress and hardening at high strain $(>70 \%){ }^{41}$ The stress-strain curves of RCM also exhibited three-stage deformation behavior, which was similar to that of PCGCM-I. In addition, RCM had a slightly higher compressive stress of $1.98 \mathrm{MPa}$ at $54.77 \%$ strain than that of PCGCM-I of $1.73 \mathrm{MPa}$ at $84.73 \%$ strain. As shown in Table 1, the incorporation of GO increased the Young's modulus of PCGCM-I, in comparison with that of RCM. Besides, the fracture compression strain of PCGCM-I and RCM was $54.77 \%$ and $84.72 \%$, respectively. The increment of fracture compression strain of PCGCM-I may be due to the great compatibility between the cellulose matrix and GO, and the interaction between these two components, ${ }^{42}$ which were demonstrated by FTIR and XRD patterns. Hence, the mechanical performance of PCGCM-I, including compression strength and fracture compression strain, was obviously better than that of cellulose/GO sheet aerogels reported in the literature. ${ }^{43}$

As shown in Figure $2 b$ and $c$, the resulting PCGCM-I adsorbent showed a smooth surface with open macropores. The pore size of PCGCM-I was larger than that of RCM. In comparison, the obtained RCM exhibited a relatively rough surface (Fig. 2d). SEM results (Fig. 2e) demonstrated that RCM displayed a distinctive honeycomb-like surface pattern, which was composed of many ridges and large holes, with a size distribution of 1-2 $\mu \mathrm{m}$. The open honeycomb-like surface was useful to improve the specific surface area and porosity of the RCM adsorbent. $^{44}$

\section{Adsorption of Ce (III) Adsorption kinetics}

The contact time of adsorbents and Ce (III) ions is of vital importance to achieve maximal capacity. Consequently, the influence of contact time on the adsorption of Ce (III) by the three adsorbents (PCGCM-I, PCGCM-II and RCM) was studied and shown in Figure 3A. The adsorption equilibrium for $\mathrm{Ce}$ (III) was reached in less than $50 \mathrm{~min}$. A rapid binding rate was observed in the initial stage of adsorption as there were more adsorption sites available at this stage. To further analyze the adsorption mechanism, adsorption kinetics were fitted by the pseudo-first order and the pseudo-second order kinetics equations, displayed as follows:

$$
\begin{aligned}
& \ln \left(q_{e}-q_{t}\right)=\ln q_{e}-k_{1} t \\
& \frac{t}{q_{t}}=\frac{1}{k_{2} q_{e}^{2}}+\frac{t}{q_{e}}
\end{aligned}
$$

where $q_{e}$ and $q_{t}\left(\mathrm{mg} \cdot \mathrm{g}^{-1}\right)$ are the adsorption capacity of $\mathrm{Ce}$ (III) at equilibrium and at the time of $t$ ( $\mathrm{min})$, respectively. $k_{l}\left(\mathrm{~min}^{-1}\right)$ is the pseudo-first order rate constant and $k_{2}$ $\left(\mathrm{g} \cdot \mathrm{mg}^{-1} \cdot \mathrm{min}^{-1}\right)$ is the rate constant of the pseudo-second order adsorption process. ${ }^{3,45}$

The linear fit the kinetic data for PCGCM-I according to the pseudo-second order kinetics equation was shown in Figure 3B. Moreover, the related parameters can be obtained by the regression of the experimental data and were listed in Table 2.

Table 1

Young's modulus and fracture compression stain of RCM and PCGCM-I

\begin{tabular}{lcc}
\hline Samples & $\begin{array}{c}\text { Young's modulus } \\
(\mathrm{MPa})\end{array}$ & $\begin{array}{c}\text { Fracture compression stain } \\
(\%)\end{array}$ \\
\hline RCM & 1.38 & 54.77 \\
PCGCM-I & 1.67 & 84.73 \\
\hline
\end{tabular}



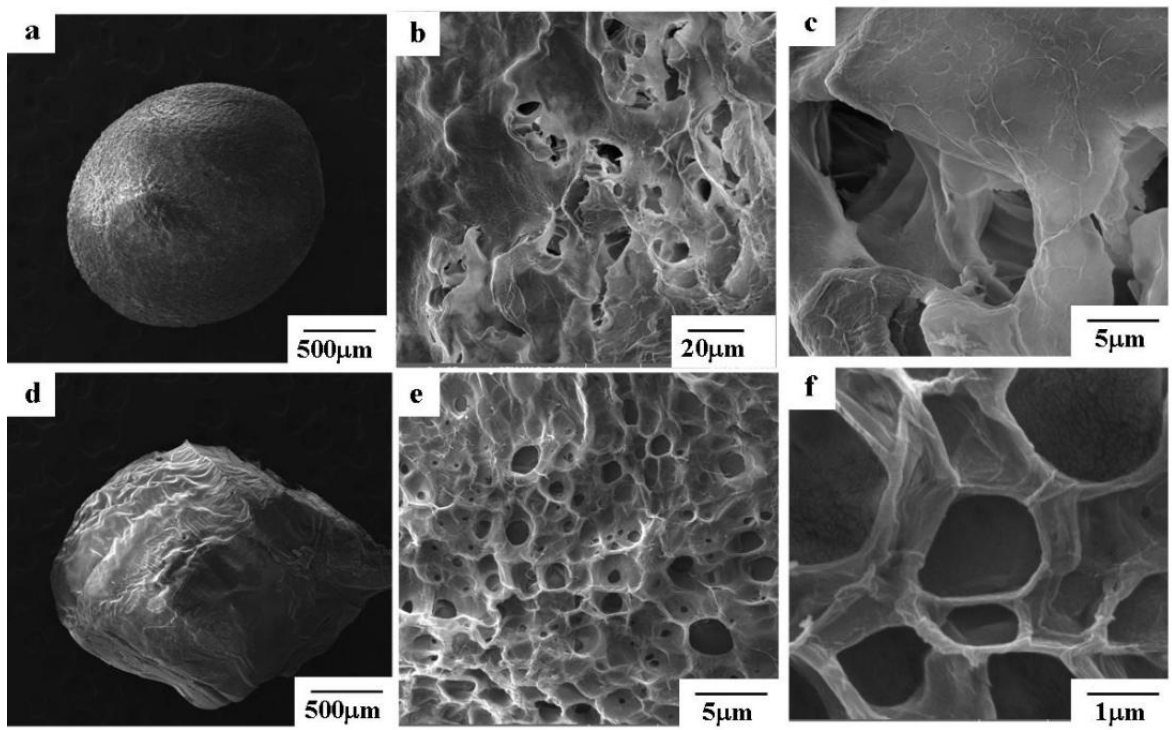

Figure 2: SEM micrographs of PCGCM-I (a, b, c) and RCM (d, e, f)
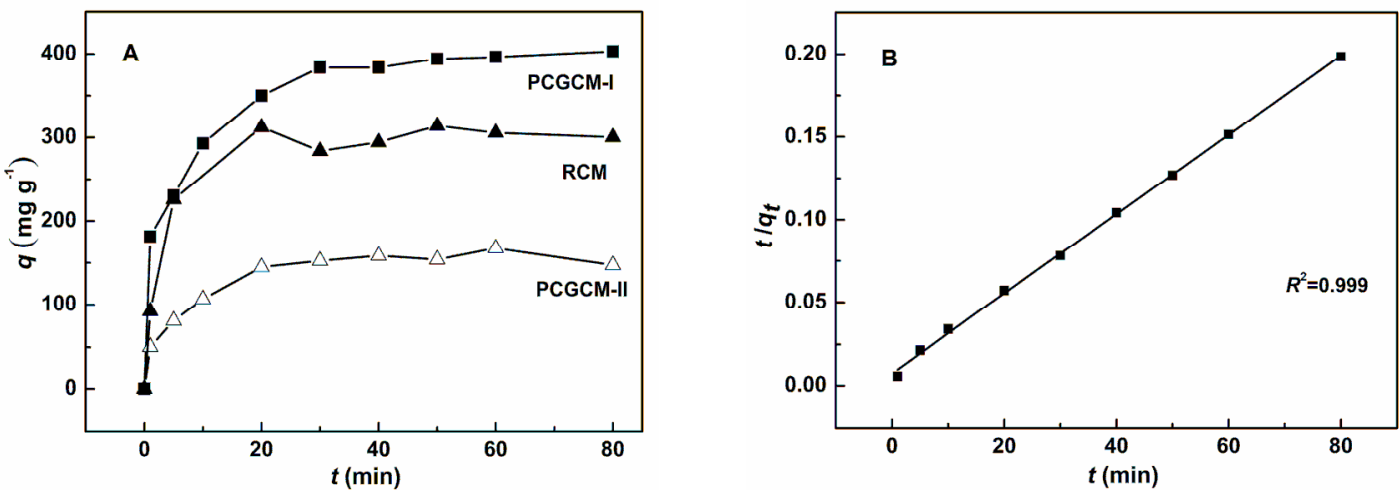

Figure 3: Adsorption kinetics of Ce (III) adsorption onto PCGCM-I, PCGCM-II and RCM (temperature: $25^{\circ} \mathrm{C}$; pH: 3.8; adsorbent dosage: $15 \mathrm{mg}$ ) (A); linear fit of the kinetic data for PCGCM-I (B)

Table 2

Fitting results by using pseudo-first order and pseudo-second order kinetic model for the adsorption of Ce (III) onto PCGCM and RCM

\begin{tabular}{lccccccc}
\hline Adsorbents & $\begin{array}{c}q_{\text {exp }} \\
\left(\mathrm{mg} \cdot \mathrm{g}^{-1}\right)\end{array}$ & $\begin{array}{c}k_{1} \\
\left(\mathrm{~min}^{-1}\right)\end{array}$ & $\begin{array}{c}q_{e} \\
\left(\mathrm{mg} \cdot \mathrm{g}^{-1}\right)\end{array}$ & $R^{2}$ & \multicolumn{3}{c}{ Pseudo-second order } \\
& 396.37 & 1.10 & 367.64 & 0.805 & 0.73 & $k_{2}$ \\
$\left(\times 10^{-3} \mathrm{~g} \cdot \mathrm{mg}^{-1} \cdot \mathrm{min}^{-1}\right)$ & $\begin{array}{c}q_{e} \\
\left(\mathrm{mg} \cdot \mathrm{g}^{-1}\right)\end{array}$ & $R^{2}$ \\
\hline PCGCM-I & 396.418 .41 & 0.999 \\
PCGCM-II & 167.40 & 2.04 & 149.25 & 0.914 & 2.13 & 161.55 & 0.987 \\
RCM & 305.53 & 2.55 & 330.033 & 0.990 & 2.47 & 309.60 & 0.998 \\
\hline
\end{tabular}

Herein, $q_{\exp }$ is the uptake of $\mathrm{Ce}$ (III) at equilibrium, which was determined by experiments. Taking PCGCM-I for example, the correlation coefficients $\left(R^{2}\right)$ and $q_{\text {exp }}$ indicated that the pseudo-second order model was more suitable to fit dynamic data than the pseudo-first order model. The result proved that the chemical interaction was involved in the adsorption. ${ }^{46}$ The adsorption behaviors of the other two adsorbents were similar. RCM exhibited a good adsorption efficiency for Ce (III), which was due to the rough surface, porous microstructure, and the oxygen atoms of the hydroxyl groups in $\mathrm{RCM}^{47}$ Compared with PCGCM-II, $q_{\text {exp }}$ of PCGCM-I increased, while $k_{2}$ decreased, implying that the chemisorption was a slow process. ${ }^{48}$ 


\section{Effects of adsorbent dosage and solution $\mathrm{pH}$ on the adsorption capacity}

Since the adsorption capacity of PCGCM-I was superior to that of the other adsorbents, the effects of adsorbent dosage and solution $\mathrm{pH}$ on the adsorption properties of Ce (III) were further investigated using PCCGM-I as adsorbent. The adsorbent loading is a crucial parameter in the adsorption process of $\mathrm{Ce}$ (III). It was studied by changing the mass of PCGCM-I with a fixed Ce (III) concentration of $140 \mathrm{mg} \cdot \mathrm{L}^{-1}$. It was evident from Figure 4A that the amount of adsorbent had a significant impact on the adsorption capacity of PCGCM-I. With the mass of adsorbent increasing from 5 to $30 \mathrm{mg}$, the $q$ value gradually reduced, as excess adsorption sites decreased the overall utilization efficiency. ${ }^{48}$

It is well known that the solution $\mathrm{pH}$ is a critical factor to control the surface electric charge of the adsorbent and the ionization degree of the adsorbate in aqueous solution. As shown in Figure 4B, the optimum $\mathrm{pH}$ range for maximum adsorption of $\mathrm{Ce}$ (III) on PCGCM-I was investigated. The results showed that the adsorption capacity increased with the increasing solution $\mathrm{pH}$ in the range from 1.0 to 5.0 and then started to drop with the further increase of $\mathrm{pH}$. For PCGCM-I, the highest adsorption capacity towards Ce (III) as high as $415.1 \mathrm{mg} \cdot \mathrm{g}^{-1}$ was obtained at $\mathrm{pH}$ 4.9. A similar phenomenon was also reported for the elimination of Ce (III) with poly (allylamine)/silica composite materials. ${ }^{49}$ Nevertheless, even when the $\mathrm{pH}$ was as low as 1.3, PCGCM-I still displayed a decent Ce (III) uptake of $60.8 \mathrm{mg} \cdot \mathrm{g}^{-1}$, relatively higher adsorption capacity than those of other adsorbents reported in

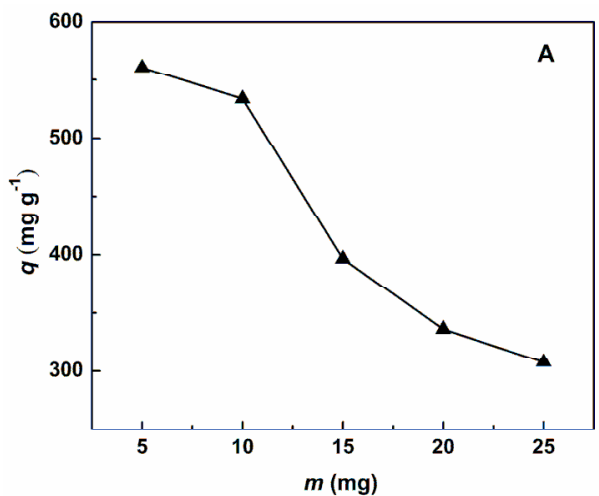

the literature. ${ }^{50,51}$ This result suggested that PCGCM had a high acid resistance and could be used in some extreme conditions. The initial increase of Ce (III) adsorption capacity with the increasing $\mathrm{pH}$ could be explained by the reduced concentration of protons and hence the decrease of competition of protons against Ce (III) for binding sites on PCGCM-I. However, the further increase in $\mathrm{pH}$ could lead to the formation of precipitates. Therefore, the decrease of Ce (III) adsorption capacity when the $\mathrm{pH}$ of the Ce (III) solution was over 7.5 was partly caused by the formation of insoluble cerium hydroxide. ${ }^{50}$

\section{Adsorption isotherm of Ce (III) onto PCGCM-I}

The adsorption isotherm of PCGCM-I is shown in Figure 5. The experimental results were fitted using the Langmuir model, displayed by Equation (4):

$q=q_{m} \times \frac{K_{L} c}{1+K_{L} c}$

where $q$ is the Ce (III) uptake, while $c$ is the adsorption capacity, $q_{m}\left(\mathrm{mg} \cdot \mathrm{g}^{-1}\right)$ is the maximum adsorption capacity and $K_{L}$ is the Langmuir constant.

The parameters and $R^{2}$ of PCGCM-I calculated by the Langmuir non-linear regression model are given in Table 3, suggesting good agreement with the fitting results using the Langmuir model. These outcomes indicated that Ce (III) was adsorbed on PCGCM-I as a monolayer. ${ }^{52}$ The maximum adsorption capacity $q_{m}$ of PCGCM-I calculated from the Langmuir model was 492.5 $\mathrm{mg} \cdot \mathrm{g}^{-1}$, which was higher than the $q_{\text {exp }}$ in Table 2.

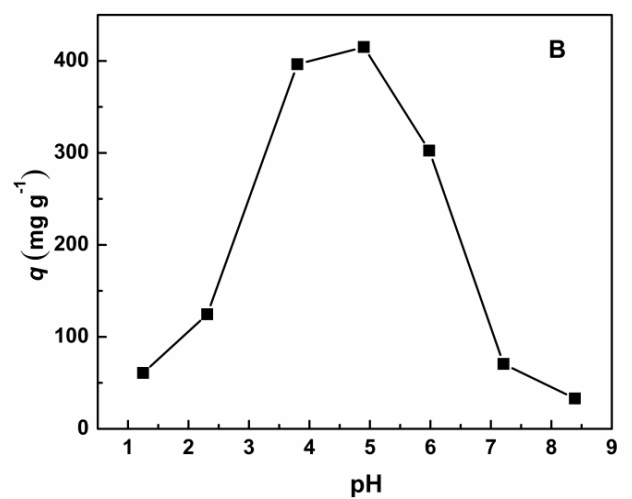

Figure 4: Effect of adsorbent dosage on Ce (III) adsorption by PCGCM-I (temperature: $25{ }^{\circ} \mathrm{C}$; $\mathrm{pH}$ : 3.8 ; adsorption time: $60 \mathrm{~min}$ ) (A); effect of solution $\mathrm{pH}$ on the removal of Ce (III) by PCGCM-I (adsorption time: 60 min; adsorbent dosage: $15 \mathrm{mg}$ ) (B) 


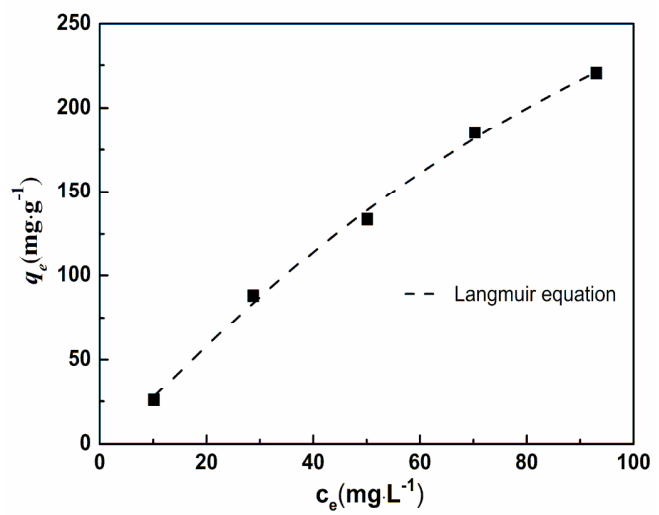

Figure 5: Adsorption isotherms of Ce (III) onto PCGCM-I (temperature: $25^{\circ} \mathrm{C} ; \mathrm{pH}$ : 3.8 ; adsorption time: $60 \mathrm{~min}$; adsorbent dosage: $15 \mathrm{mg}$ )

Table 3

Isotherm parameters of PCGCM-I fitted by Langmuir model

\begin{tabular}{lccc}
\hline \multirow{2}{*}{ Model } & \multicolumn{3}{c}{ Langmuir } \\
\cline { 2 - 4 } & $q_{m}\left(\mathrm{mg} \cdot \mathrm{g}^{-1}\right)$ & $K_{L}\left(\mathrm{~L} \cdot \mathrm{mg}^{-1}\right)$ & $R^{2}$ \\
\hline PCGCM-I & 492.5 & 0.00394 & 0.996 \\
\hline
\end{tabular}

This may be explained by the fact that Ce (III) might not form a monolayer on the adsorbent. In addition, the $q_{m}$ value of PCGCM-I was obviously better than that of most reported adsorbents, ${ }^{3,50,51,53,54}$ demonstrating that PCGCM-I is a promising material for $\mathrm{Ce}$ (III) removal.

\section{Adsorption mechanism and regeneration}

According to previous studies, the adsorption mechanisms of Ce (III) mainly consists of surface complexation, ion exchange and electrostatic attraction. ${ }^{55,56}$ The schematics of the adsorption mechanism is shown in Figure 6. As illustrated in Figure 6 and Equations (5)-(8), the surface complexation, ion exchange and electrostatic attraction mainly occur between Ce (III) and the oxygenous functional groups of PCGCM, such as carboxyl groups $(-\mathrm{COOH})$ and hydroxyl groups $(-\mathrm{OH}){ }^{57}$ When Ce (III) ions were exchanged with $\mathrm{Na}^{+}, \mathrm{Mg}^{2+}, \mathrm{K}^{+}$or $\mathrm{Ca}^{2+}$ ions, the binding strengths were weak and easily replaced, thus ion exchange occurred.

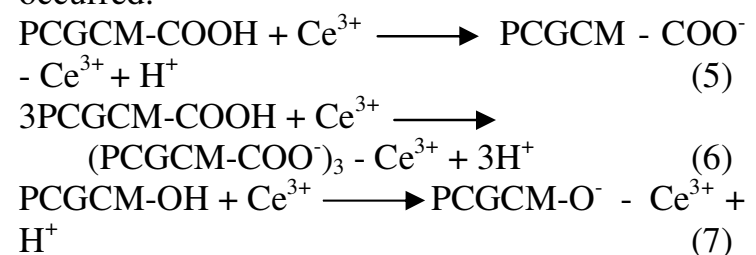

$$
3 \mathrm{PCGCM}-\mathrm{OH}+\mathrm{Ce}^{3+} \longrightarrow\left(\mathrm{PCGCM}-\mathrm{O}^{-}\right)_{3}-
$$$$
\mathrm{Ce}^{3+}+3 \mathrm{H}^{+}
$$

To obtain further elucidation of the mechanisms of $\mathrm{Ce}$ (III) adsorption onto PCGCM-I, the adsorbents were analyzed by XPS after adsorption and desorption in $\mathrm{NaCl}$ solution, and the results are shown in Figure 7. After the adsorption, two typical $\mathrm{Ce}_{3 \mathrm{~d}}$ peaks were observed at $\mathrm{BE}$ of 885.3 and $904.9 \mathrm{eV}$, indicating that the Ce (III) was successfully adsorbed on PCGCM-I (Fig. 7B) ${ }^{58}$ After the desorption using $1 \mathrm{M} \mathrm{NaCl}$, a new peak of ca. $1071.8 \mathrm{eV}$ showed up, corresponding to the binding energy of $\mathrm{Na}_{1 \mathrm{~s}}$ (Fig. 7C). Therefore, the result suggested that Ce (III) ions were adsorbed onto the PCGCM-I adsorbent most likely by the ion exchange mechanism, and it was consistent with the adsorption kinetics result.

The regeneration ability is important for the practical application of adsorbents. The adsorption-desorption cycles were conducted for three times and the adsorption capacities in each cycle are shown in Figure 8. After the third cycle, the adsorption capacity of PCGCM-I still remained at a high level of $187.7 \mathrm{mg} \cdot \mathrm{g}^{-1}$, indicating the obtained adsorbents had an excellent regeneration ability. 


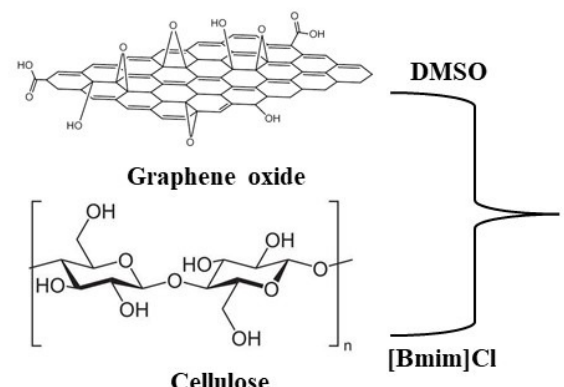

Cellulose

.......... Hydrgen Bonding

- $\mathrm{Ce}^{3+}$
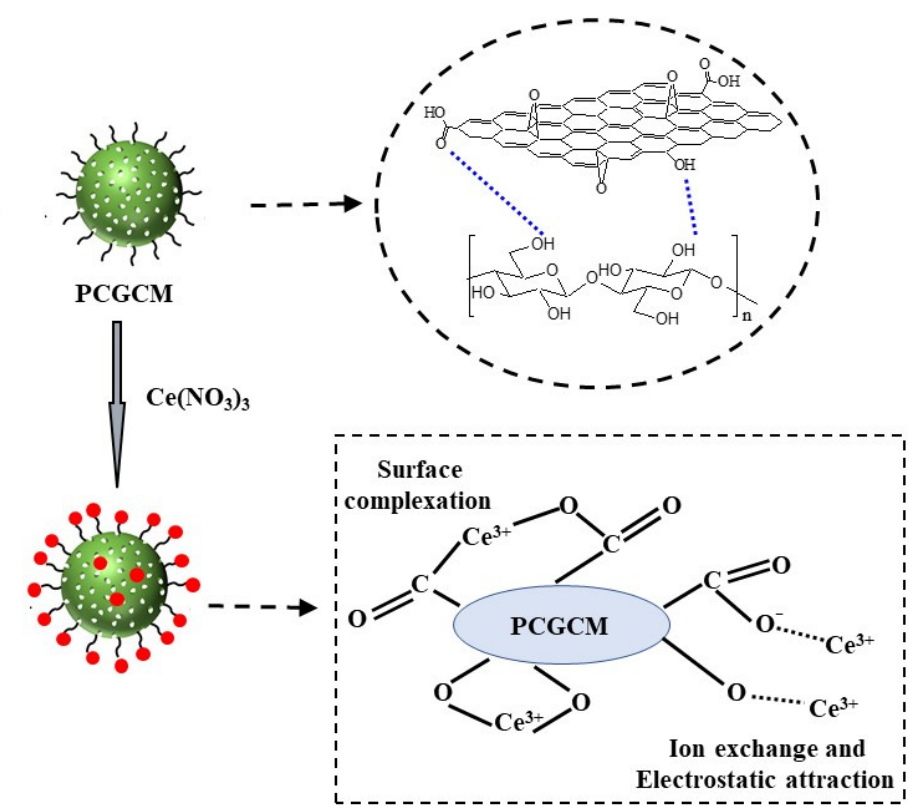

Figure 6: Schematics of adsorption mechanism of Ce (III) onto PCGCM adsorbent
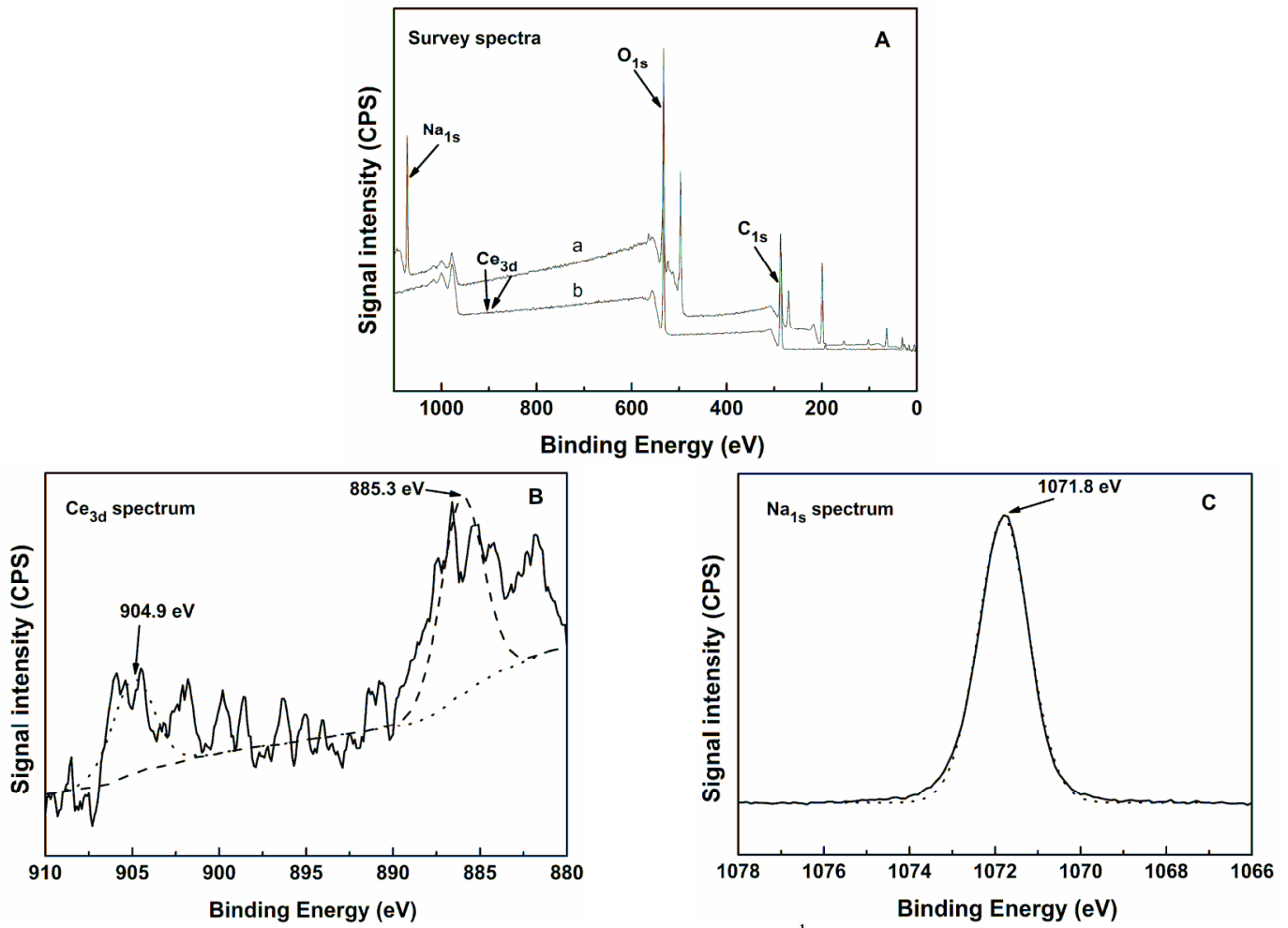

Figure 7: XPS spectra of PCGCM-I after desorption using $1 \mathrm{~mol} \cdot \mathrm{L}^{-1} \mathrm{NaCl}$ (a) and PCGCM-I after adsorption of $\mathrm{Ce}$ (III) (b) (A); $\mathrm{Ce}_{3 \mathrm{~d}}$ curve-fitting of PCGCM-I after adsorption of Ce (III) (B); $\mathrm{Na}_{1 \mathrm{~s}}$ curve-fitting of PCGCM-I after desorption in $\mathrm{NaCl}$ (C) 


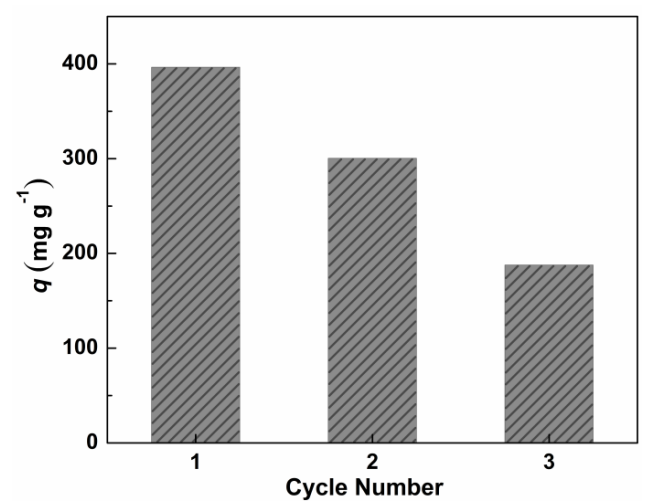

Figure 8: Ce (III) uptake of PCGCM-I in three cycles by using $1 \mathrm{~mol} \cdot \mathrm{L}^{-1} \mathrm{HCl}$ as eluent (temperature: $25^{\circ} \mathrm{C}$; pH: 3.8; adsorption time: $60 \mathrm{~min}$; adsorbent dosage: $15 \mathrm{mg}$ )

\section{CONCLUSION}

A novel porous cellulose/GO composite microsphere adsorbent for highly effective adsorption of Ce (III) ions was prepared in ionic liquid. The adsorbents were characterized by FTIR, TGA, XRD and SEM. Porous morphology, spherical shape, and enhanced mechanical properties of the PCGCM adsorbent all contributed to effective adsorption. The adsorption was rapid as adsorption equilibrium was reached within $50 \mathrm{~min}$. The kinetic study showed that the pseudo-second order kinetic model was well suited to describe the adsorption process. It was also found that the solution $\mathrm{pH}$ played an important role in the adsorption process. For PCGCM-I, the highest adsorption capacity towards Ce (III) as high as $415.1 \mathrm{mg} \cdot \mathrm{g}^{-1}$ was obtained at a $\mathrm{pH}$ of 4.9. Even under extreme conditions, such as in the strong acidic solution with $\mathrm{pH}$ 1.3, the adsorbent still had a considerable Ce (III) uptake of $60.8 \mathrm{mg} \cdot \mathrm{g}^{-1}$. The dominant adsorption mechanism of PCGCM was ion-exchange, as confirmed by the XPS analysis. Moreover, the maximum theoretical adsorption capacity of PCGCM for Ce (III) was $492.5 \mathrm{mg} \cdot \mathrm{g}^{-1}$, which was much higher than that obtained in our previous work using the $\mathrm{GO} /$ cellulose composite film. Besides, the adsorption capacity of PCGCM-I still remained at a high level of 187.7 $\mathrm{mg} \cdot \mathrm{g}^{-1}$ after three cycles of adsorption and desorption. Thus, this study provides a novel, highly efficient and environmentally friendly adsorbent for the removal of REEs, such as Ce (III) ions, from wastewater.

ACKNOWLEDGEMENTS: This research was funded by National Natural Science Foundation of China (NNSFC, No. 11965015), Development Plan of Young Scientific and Technological Talents in Colleges and Universities in Inner Mongolia (No. NJYT22072) and Outstanding Youth Fund Project of Inner Mongolia University of Science and Technology (No. 2019YQL05). This work is also supported by the Innovation Fund of Inner Mongolia University of Science and Technology (2018QDL-B01), the Natural Science Foundation of Inner Mongolia (2019BS05022) and the Inner Mongolia Science and Technology Project Plan (NJZZ20087).

\section{REFERENCES}

1 T. Ogata, H. Narita and M. Tanaka, Hydrometallurgy, $\quad \mathbf{1 5 2}, \quad 178 \quad$ (2015), https://doi.org/10.1016/j.hydromet.2015.01.005

2 Y. Wang, D. Wang, N. H. Yi, P. Sheng and B. Yang, Int. Arch. Nurs. Health Care, 5, 1 (2019), https://doi.org/10.1016/j.hydromet.2015.01.005

3 Y. Zhu, Y. Zheng and A. Wang, J. Environ. Chem. Eng., $\quad 3, \quad 1416 \quad$ (2015), https://doi.org/10.1016/j.jece.2014.11.028

M. Gras, N. Papaiconomou, E. Chainet, F. Tedjar and I. Billard, Sep. Purif. Technol., 178, 169 (2017), https://doi.org/10.1016/j.seppur.2017.01.035

5 M. Teramoto, S. S. Fu, K. Takatani, N. Ohnishi, T. Maki et al., Sep. Purif. Technol., 18, 57 (1999), https://doi.org/10.1016/S1383-5866(99)00050-7

6 M. Rafatullah, O. Sulaiman, R. Hashim and A. Ahmad, J. Hazard. Mater., 177, 70 (2010), https://doi.org/10.1016/j.jhazmat.2009.12.047

7 S. Yang, Y. Chang, H. Wang, G. Liu, S. Chen et al., J. Colloid Interface Sci., 351, 122 (2010), https://doi.org/10.1016/j.jcis.2010.07.042

8 R. Sitko, E. Turek, B. Zawisza, E. Malicka, E. Talik et al., Dalton Trans., 42, 5682 (2013), https://doi.org/10.1039/c3dt33097d

B. Wang, W. Lou, X. Wang and J. Hao, J. Mater. Chem., 22, $12859 \quad$ (2012), https://doi.org/10.1039/c2jm31635h 
10 M. H. Sadeghi, M. A. Tofighy and T. Mohammadi, Chemosphere, 253, $126647 \quad$ (2020), https://doi.org/10.1016/j.chemosphere.2020.126647

11 H.-A. S. Tohamy, S. Kamel and M. El-Sakhawy, Cellulose Chem. Technol., 55, 417 (2021), https://doi.org/10.35812/CelluloseChemTechnol.2021. 55.39

12 R. Sitko, M. Musielak, B. Zawisza, E. Talik and A. Gagor, $R S C \quad A d v$., 6, $96595 \quad$ (2016), https://doi.org/10.1039/C6RA21432K

${ }^{13}$ H. Shi, W. Li, L. Zhong and C. Xu, Ind. Eng. Chem. $\begin{array}{llll}\text { Res., } & \mathbf{5 3} & 1108 & \text { (2014), }\end{array}$ https://doi.org/10.1021/ie4027154

14 M. A. K. Moharram, K. Tohami, W. M. El Hotaby and A. M. Bakr, React. Funct. Polym., 101, 9 (2016), https://doi.org/10.1016/j.reactfunctpolym.2016.02.001

15 S. Mahmoudian, M. U. Wahit, A. F. Ismail and A. A. Yussuf, Carbohyd. Polym., 88, 1251 (2012), https://doi.org/10.1016/j.carbpol.2012.01.088

16 D. Han, L. Yan, W. Chen, W. Li and P. R. Bangal, Carbohyd. Polym., 83, $966 \quad$ (2011), https://doi.org/10.1016/j.carbpol.2010.09.006

17 B. Qiu, T. Sun, M. Li, Y. Chen, S. Zhou et al., Compos. Part A, 139, $106092 \quad$ (2020), https://doi.org/10.1016/j.compositesa.2020.106092

18 M. Xu, Q. Huang, X. Wang and R. Sun, Ind. Crop. Prod., $\quad$ 70, $56 \quad$ (2015), https://doi.org/10.1016/j.indcrop.2015.03.004

19 X. Zhang, H. Yu, H. Yang, Y. Wan, H. Hu et al., J. Colloid Interface Sci., 437, 277 (2015), https://doi.org/10.1016/j.jcis.2014.09.048

20 X. Liu, Y. Zhou, W. Nie, L. Song and P. Chen, J. Mater. Sci., 50, $\quad 6113 \quad$ (2015), https://doi.org/10.1007/s10853-015-9166-y

21 X. Ma, C. Liu, D. P. Anderson and P. R. Chang, Chemosphere, $\quad \mathbf{1 6 5}, \quad 399 \quad$ (2016), https://doi.org/10.1016/j.chemosphere.2016.09.033

22 R. P. Swatloski, S. K. Spear, J. D. Holbrey and R. D. Rogers, J. Am. Chem. Soc., 124, 4974 (2002), https://doi.org/10.1021/ja025790m

23 M. Kosmulski, J. Gustafsson and J. B. Rosenholm, Thermochim. Acta, 412, $47 \quad$ (2004), https://doi.org/10.1016/j.tca.2003.08.022

${ }^{24}$ Y. Hao, J. Peng, J. Li, M. Zhai and G. Wei, Carbohyd. Polym., 77, $779 \quad$ (2009), https://doi.org/10.1016/j.carbpol.2009.02.025

${ }_{25}$ Y. Hao, Y. Cui, J. Peng, N. Zhao, S. Li et al., Carbohyd. Polym., 208, $269 \quad$ (2019), https://doi.org/10.1016/j.carbpol.2018.12.068

26 D. I. Fried, F. J. Brieler and M. Frba, ChemCatChem, $\quad 5, \quad 862 \quad$ (2013), https://doi.org/10.1002/cctc.201200640

27 J. A. Woods, R. Lalrempuia, A. Petronilho, N. D. McDaniel, H. Muller-Bunz et al., Energ. Environ. Sci., 7, 2316 (2014), https://doi.org/10.1039/C4EE00971A

28 N. V. Deorkar and S. M. Khopkar, Analyst, 114, 105 (1989), http://doi.org/10.1039/an9891400105
29 D. M. Suflet, G. C. Chitanu and V. I. Popa, React. Funct. Polym., 66, $1240 \quad$ (2006), https://doi.org/10.1016/j.reactfunctpolym.2006.03.006 30 G. He, W. Liu, X. Sun, Q. Chen, X. Wang et al., Mater. Res. Bull., 48, $1885 \quad$ (2013), https://doi.org/10.1016/j.materresbull.2013.01.038

31 T. A. Saleh, A. Sar1 and M. Tuzen, Chem. Eng. J., 307, 230

(2017),

https://doi.org/10.1016/j.cej.2016.08.070

${ }^{32}$ G. He, H. Chen, J. Zhu, F. Bei, X. Sun et al., J. Mater. Chem., 21, $14631 \quad$ (2011), https://doi.org/10.1039/C1JM12393A

33 F. Ren, Z. Li, W. Tan, X. Liu, Z. Sun et al., J. Colloid Interface Sci., 532, 58 (2018), https://doi.org/10.1016/j.jcis.2018.07.1011

34 R. Li, C. Chang, J. Zhou, L. Zhang, W. Gu et al., Ind. Eng. Chem. Res., 49, 11380 (2010), https://doi.org/10.1021/ie101144h

35 S. Raymond, A. Kvick and H. Chanzy, Macromolecules, 28, $8422 \quad$ (1995), https://doi.org/10.1021/ma00128a063

${ }^{36}$ H. Zhang, J. Wu, J. Zhang and J. He, Macromolecules, 38, $8272 \quad$ (2005), https://doi.org/10.1021/ma0505676

37 Y. Zhang, Y. Liu, X. Wang, Z. Sun, J. Ma et al., Carbohyd. Polym., 101, $392 \quad$ (2014), https://doi.org/10.1016/j.carbpol.2013.09.066

38 J.-I. Kadokawa, M.-A. Murakami, A. Takegawa and Y. Kaneko, Carbohyd. Polym., 75, 180 (2009), https://doi.org/10.1016/j.carbpol.2008.07.021

39 Y. Zhang, H. Ma, Q. Zhang, J. Peng, J. Li et al., J. Mater. Chem., 22, $13064 \quad$ (2012), https://doi.org/10.1039/C2JM32231E

40 C.-J. Kim, W. Khan, D.-H. Kim, K.-S. Cho and S.-Y. Park, Carbohyd. Polym., 86, 903 (2011), https://doi.org/10.1016/j.carbpol.2011.05.041

${ }^{41}$ X. Ge, Y. Shan, L. Wu, X. Mu, H. Peng et al., Carbohyd. Polym., 197, 277 (2018), https://doi.org/10.1016/j.carbpol.2018.06.014

${ }^{42}$ M. Tian, L. Qu, X. Zhang, K. Zhang, S. Zhu et al., Carbohyd. Polym., 111, $456 \quad$ (2014), https://doi.org/10.1016/j.carbpol.2014.05.016

43 J. Zhang, Y. Cao, J. Feng and P. Wu, J. Phys. Chem. $C, \quad$ 116, $8063 \quad$ (2012), https://doi.org/10.1021/jp2109237

44 Y. Wan, F. Zhang, C. Li, G. Xiong, Z. Yong et al., J. Mater. Chem. A, 3, 24389 (2015), https://doi.org/10.1039/C5TA07464A

${ }^{45}$ M. Najafi Lahiji, A. R. Keshtkar and M. A. Moosavian, Particul. Sci. Technol., 36, 340 (2018), https://doi.org/10.1080/02726351.2016.1248262

46 L. Zhao, J. Sun, Y. Zhao, L. Xu and M. Zhai, Chem. Eng. $\quad J$., $\quad \mathbf{1 7 0}, 162 \quad$ (2011), https://doi.org/10.1016/j.cej.2011.03.047

47 J. Wang, L. Wei, Y. Ma, K. Li, M. Li et al., Carbohyd. Polym., 98, $736 \quad$ (2013), https://doi.org/10.1016/j.carbpol.2013.06.001 


\section{Cellulose}

48 M. Xu, Y. Ao, S. Wang, J. Peng, J. Li et al., Carbohyd. Polym., 128, $171 \quad$ (2015), https://doi.org/10.1016/j.carbpol.2015.04.018

49 S. Zhou, X. Li, Y. Shi, A. Alshameri and C. Yan, Desalin. Water Treat., 56, $1321 \quad$ (2014), https://doi.org/10.1080/19443994.2014.944221

50 Ş. Sert, C. Kütahyali, S. İnan, Z. Talip, B. Çetinkaya et al., Hydrometallurgy, 90, 13 (2008), https://doi.org/10.1016/j.hydromet.2007.09.006

51 C. Kütahyali, Ş. Sert, B. Çetinkaya, S. Inan and M. Eral, Sep. Sci. Technol., 45, 1456 (2010), http://dx.doi.org/10.1080/01496391003674266

52 Y. Zhang, H. Ma, J. Peng, L. Xu, J. Li et al., Desalin. Water Treat., 105, 255 (2018), https://doi.org/10.5004/dwt.2018.21988

53 F. N. Behdani, A. T. Rafsanjani, M. Torab-Mostaedi and S. M. A. K. Mohammadpour,
Korean J. Chem. Eng., 30, 448 (2013), https://doi.org/10.1007/s11814-012-0126-9

54 L. X. Hou, F. Jiang and S. Wang, J. Anal. Chem., 63, 337

(2008),

https://doi.org/10.1134/S1061934808040059

55 Q. Kong, X. Shi, W. Ma, F. Zhang, T. Yu et al., J. Hazard. Mater., 415, $125690 \quad$ (2021), https://doi.org/10.1016/j.jhazmat.2021.125690

56 J. He, Y. Xu, W. Wang, B. Hu, Z. Wang et al., Chem. Eng. J., 379, 122431 (2020), https://doi.org/10.1016/j.cej.2019.122431

57 Y. Cao, W. Xiao, G. Shen, G. Ji, Y. Zhang et al., Bioresour. Technol., 273, 70 (2019), https://doi.org/10.1016/j.biortech.2018.10.065

58 E. Paparazzo, Chem. Eng. J., 170, 342 (2011), https://doi.org/10.1016/j.cej.2011.01.085 